\title{
Evaluating Preceptor Perception of Role Development and Support Initiatives in a Collaborative Bachelor of Science in Nursing Program
}

Florence Loyce Luhanga

University of Regina, florence.luhanga@uregina.ca

Sheri McCrystal

Saskatchewan Polytechnic, sheri.mccrystalch@saskpolytech.ca

Elizabeth Domm

University of Regina, liz.domm@uregina.ca

Follow this and additional works at: https://qane-afi.casn.ca/journal

Part of the Other Nursing Commons

\section{Recommended Citation}

Luhanga, Florence Loyce; McCrystal, Sheri; and Domm, Elizabeth (2020) "Evaluating Preceptor Perception of Role Development and Support Initiatives in a Collaborative Bachelor of Science in Nursing Program," Quality Advancement in Nursing Education - Avancées en formation infirmière: Vol. 6: Iss. 3, Article 2.

DOI: https://doi.org/10.17483/2368-6669.1241

This Article is brought to you for free and open access by Quality Advancement in Nursing Education - Avancées en formation infirmière. It has been accepted for inclusion in Quality Advancement in Nursing Education - Avancées en formation infirmière by an authorized editor of Quality Advancement in Nursing Education - Avancées en formation infirmière. 


\section{Evaluating Preceptor Perception of Role Development and Support Initiatives in a Collaborative Bachelor of Science in Nursing Program}

\section{Cover Page Footnote}

Acknowledgement: This research was funded by INS Research - Saskatchewan Polytechnic/University of Regina Collaborative Grant Professional Development - School of Nursing and School of Health Sciences. We would also like to acknowledge Sharon Dixon and Patricia Christie, as well as all the preceptors who participated in this research. Remerciements: Cette recherche a été financée par I'Institute of Nursing Scholarship Research - Saskatchewan Polytechnic/University of Regina Collaborative Grant Professional Development - School of Nursing et School of Health Sciences. Nous aimerions aussi remercier Sharon Dixon, Patricia Christie et toutes les préceptrices ayant pris part à cette étude. 
Nurse preceptors fulfil a vital role in the success of preceptorship experiences during the clinical education of nursing students in their final year of study. Evidence suggests that this success depends greatly on adequate preceptor role preparation and support (Blum, 2014; Luhanga et al., 2010; Myrick et al., 2011). Many scholars have highlighted the importance of a formal preparatory or educational program for preceptors (Horton et al., 2012; Kalischuk et al., 2013; Luhanga, et al., 2010; Myrick et al., 2011). However, despite these observations, research indicates that preceptors often believe that they were not adequately prepared for their preceptor role, leaving them to rely on previous experience (Broadbent et al., 2014; Dahlke et al., 2016; Luhanga et al., 2010).

While the literature offers some insights into what preceptors might find supportive, it does not provide us insight into their perceptions about whether they feel supported and confident in their knowledge about how to guide undergraduate nursing students in complex clinical learning environments. Dahlke et al. (2016) suggest undergraduate programs need to have an understanding of what preceptors' concerns and needs are as this can lead to a more rewarding teaching experience by the preceptor and faculty, which enhances student learning and quality of care for patients. Currently, no study has been conducted within this Prairie province to explore preceptors' perceptions about their role development and support. Therefore, the purposes of this study were to (a) explore this Prairie province preceptors' perceptions of their role preparation/development and support needed to facilitate student learning experiences, and (b) suggest possible strategies to enhance preceptors' support to ensure quality learning by students, which in turn enhances competent, safe patient care.

\section{Background and Literature Review}

As indicated in the literature, preceptors encounter many challenges as they assume their unique role. These challenges include complex and increased workloads (Haggerty et al., 2012; Kalischuk et al., 2013), ineffective communication with nursing faculty which can lead to preceptors feeling excluded, the student evaluation process (Liu et al., 2010; Luhanga et al., 2008; Yonge et al., 2011), and lack of or ineffective feedback on their role (McSharry \& Lathlean, 2017). Furthermore, preceptors report limited time available to fully enact their role (Dahlke et al., 2016; Kalischuk et al., 2013; Liu et al., 2010) and engage with nursing students (Butler et al., 2011). Preceptors also report insufficient communication with their nursing colleagues (Dahlke et al., 2016; Kalischuk et al., 2013; Liu et al., 2010) and perceive a lack of support, particularly when dealing with students who display unsafe clinical practice (Larocque \& Luhanga, 2013; Luhanga et al., 2008). Preceptors expressed a need for more supportive mentoring from their clinical managers, nursing peers, and clinical faculty (Blum, 2014; Dahlke et al., 2016; Kalischuk et al., 2013; Luhanga et al., 2010).

\section{Perception of Support for the Preceptor Role}

Dibert and Goldenberg (1995) were among the first researchers to investigate whether the relationship between Canadian preceptors' commitment to the preceptor role is positively correlated to their perception of benefits, rewards, and support. In another Canadian study, Hyrkäs and Shoemaker (2007) replicated the earlier study with similar findings; in addition, they found that ongoing preceptor support was needed from faculty. McCarthy and Murphy (2010) in Ireland, revealed that the majority of preceptors found their role stressful and burdensome, and did not feel adequately supported by their clinical managers; specifically, only $33.5 \%$ reported receiving support from their hospital management team. Preceptors expressed the need for protected time, 
support, feedback, and recognition from management for undertaking this role. Conversely, Butler et al. (2011) revealed that $57 \%$ of the preceptors in Ireland perceived that the preparation they had received was sufficient in supporting their preceptor role, while $40 \%$ believed it was minimal, and $3 \%$ felt it was excessive. The most frequently used sources of support for preceptors were communicating with other preceptors (56.7\%), referring to competency assessment guidelines (56.7\%), and consulting material from a preceptor education course (29.4\%). Similarly, Hautala, Saylor, and O'Leary-Kelley (2007), in their US study, found many preceptors felt adequately supported (88\%).

\section{Preceptor Support Initiatives}

Because preceptors play a vital role in the success of the preceptorship experience and in the preparation of the nursing student as a safe and competent beginning practitioner (Myrick \& Yonge, 2005), research indicates preceptors need support to effectively perform their role (e.g., Blum, 2014; DeWolfe et al., 2010; Luhanga et al., 2010). Horton and colleagues (2012) suggest that after initial preceptor workshops or education, preceptors need and desire ongoing support. Other scholars also acknowledge that the preceptor role takes time to develop and requires both initial and ongoing education and professional support (Lazarus, 2016). Bowen, Fox, and Burridge (2012) assert that once support is accomplished, an improved ability to undertake the preceptor role and responsibilities leads to enhanced job satisfaction. In agreement, DeWolfe et al. (2010) explain that providing appropriate support to preceptors can enhance their role success. Other scholars concur that perceived preceptor support has been related to role satisfaction, teaching effectiveness, and role commitment (Blum, 2014; Dibert \& Goldenberg, 1995; Kalischuk et al., 2013).

Scheduling challenges, burdensome workload responsibilities, and competing priorities during work hours and beyond were cited as the major barriers to participating in preceptor preparation initiatives (Luhanga et al., 2010). Haggerty et al. (2012) suggested that creative teaching strategies are required to support preceptors in accessing appropriate education for their role. Best practices for ongoing support for preceptors include flexible delivery options that do not increase preceptor workload (Blum, 2014; DeWolfe et al., 2010; Myrick et al., 2011).

Myrick et al. (2011), for example, investigated the efficacy of virtual learning spaces in supporting preceptorship. Study findings showed that the program was informative, supportive and highly valued by preceptors, affirming that online preceptor support can work. Blum (2014) tested the use of educational technology in the form of podcasts "demonstrating how a preceptor could constructively approach difficult situations using caring behaviors to engage novice nurses and to examine the relationship between preceptor support and role commitment" (p. 1). Results revealed a strong correlation between the preceptor's perception of support and commitment to the role. Similarly, Lee and colleagues (2017) developed a nurse preceptor-centred education program in Taiwan, and concluded that without input from the learner, preceptor education programs do not meet the learning needs of the preceptors.

There are a number of ongoing initiatives for preceptor role development and support within the western Canadian province. For example, at the provincial level, between September and October 2015, the provincial Academic Health Sciences Network (AHSN) organized interprofessional preceptor conferences in three locations. The AHSN also launched a new preceptor website designed to provide education and support to preceptors or supervisors from any health science discipline. In addition, two undergraduate nursing education programs, in conjunction 
with the provincial health districts, have been offering organized formal preceptorship workshops throughout the province. The collaborative Bachelor of Science in nursing $(\mathrm{BScN})$ program also developed a preceptor manual and guide for preceptors to reference throughout the clinical experience. The manual and guide are provided for all preceptors before commencement of the students' clinical experiences. To date, the efficacy of these programs and resources to support preceptor' perceptions of their role preparation and role development has not been explored.

\section{Research Questions}

The following questions guided this study: (1) What are the preceptors' perceptions of their role preparation, and what role development is needed to facilitate clinical learning experiences for nursing students? and (2) How do preceptors perceive the support they receive to facilitate clinical learning experiences for nursing students?

\section{Methods}

\section{Design}

A cross-sectional correlational study design was used. After receiving ethics board approval, survey questions were developed and refined. Potential preceptor respondents who had previously worked as preceptors with fourth-year nursing students from the collaborative program were invited to complete an online Qualtrics survey.

\section{Sample and Setting}

The sample for this study were all registered nurses (RNs) and registered psychiatric nurses (RPNs) who had previously precepted fourth-year nursing students from the collaborative $\mathrm{BScN}$ program.

\section{Ethical Consideration}

Ethics board approvals were obtained before recruitment and data collection. Participants were informed that participation was voluntary, that their responses were anonymous, and that they could withdraw from the study at any time by exiting the survey before completion without penalty. Completion and submission of the online survey was considered as implied consent. Participants were further informed that once survey data were submitted, because they were anonymous, their responses could not be withdrawn.

\section{Data Collection and Instrument}

Survey data collection occurred from October 2017 to April 2018. Survey questions were developed by researchers based on previous literature (Broadbent et al., 2014; Dahlke et al., 2016; Dibert \& Goldenberg, 1995) and entered into Qualtrics. Survey questions were pilot tested by two nursing faculty colleagues who were not engaged in the study to assess overall structure and readability of questions and statements. Based on their feedback, minor changes were made to refine the instrument before final administration. A self-administered survey was selected to allow respondents to complete the survey in their own time, to preserve respondents' anonymity, and to ensure researcher bias was not a factor (Rice et al., 2017).

The survey consisted of two sections. Section one contained demographic questions (age, areas of practice, nursing education, years of practice, and number of times respondents had preceptored students). Section two contained items asking preceptors to rate their perceptions regarding (a) preceptor's role preparation, (b) resource material, (c), faculty support, and (d) 
faculty contact. Items used a 5-point Likert scale ranging from strongly agree, agree, neither agree nor disagree, disagree, and strongly disagree.

\section{Data Analysis}

R statistical computing language ( $\mathrm{R}$ Core Team, 2014) was used to conduct the analysis. Demographic data were sorted and categorized by demographic identifiers into subgroups (primary environment - acute versus community, primary area of practice, nursing education, and years of practice) and analyzed using descriptive statistics (e.g., frequencies and percentages).

Items from section two were organized to form four ad-hoc subscales (materials, student, preparation, and faculty interaction). Analysis of responses was conducted using Shapiro-Wilk test of normality and quantile-quantile plots to ascertain whether the use of non-parametric statistical analysis was appropriate for this data set. The Wilcoxon Rank-Sum Test (MannWhitney U) was applied to test for statistically significant differences in demographic subgroups across subscales and individual question responses (Polit \& Beck, 2017). Reliability was measured in two ways. First, the consistency with which survey questions measured preceptors' perceptions as intended were analyzed for the four subscales using R Package Psych (Revelle, 2015). Second, Cronbach's alpha (raw and standardized) was used to measure internal consistency (Polit \& Beck, 2017). Subscale inter-correlations and item-specific statistics were calculated and Fisher's exact test (FET) was applied to test differences among subscale scores in relation to demographic groups (Polit \& Beck, 2017).

\section{Results}

\section{Demographic Data}

From the 659 emails that were sent out to potential participants, 161 surveys were returned, resulting in a response rate of $24.4 \%$. However, after removal of 33 majority-blank records and surveys in which the box to consent to participate was not checked, data from 128 valid surveys were analyzed (adjusted response rate of 19.4\%). Table 1 presents the frequency and percent of responses by demographic question and category for select demographic questions. The age of the respondents ranged from 20 to more than 60 years old. The majority of the respondents (64\%) were 49 years old or younger. Seventy percent of respondents had a bachelor's degree, $27 \%$ had a diploma, and 4\% had completed a master's degree. Further, the results showed that study respondents practiced in various health care settings including acute care, critical care, community/home care, public health, mental health, rural, and pediatrics. Fifty-eight percent of respondents worked in a hospital while $36 \%$ worked in the community. The study respondents' years of nursing experience varied from less than 5 years to more than 30 years. Most respondents $(57 \%)$ reported precepting students primarily in hospitals, approximately $36 \%$ in community, and $5 \%$ in residential care.

\section{Table 1}

Demographic Data of Preceptor Respondents $(n=128)$

\begin{tabular}{|c|c|c|}
\hline Demographic factor & Frequency $(n)$ & Percent \\
\hline Age (years) & & \\
\hline $20-29$ & 15 & 12.00 \\
\hline $30-39$ & 30 & 23.43 \\
\hline $40-49$ & 37 & 29.00 \\
\hline $50-59$ & 37 & 29.00 \\
\hline
\end{tabular}




\begin{tabular}{|c|c|c|}
\hline 60 or more & 9 & 7.03 \\
\hline Education & 35 & 27.3 \\
\hline \multicolumn{3}{|l|}{ Diploma } \\
\hline Baccalaureate & 87 & 68.0 \\
\hline Master's degree & 5 & 3.9 \\
\hline Other & 1 & 0.78 \\
\hline \multicolumn{3}{|l|}{ Area of practice } \\
\hline Acute & 42 & 32.81 \\
\hline Acute, critical care & 15 & 11.72 \\
\hline $\begin{array}{l}\text { Community health, home } \\
\text { care }\end{array}$ & 12 & 9.38 \\
\hline Long-term care & 7 & 5.47 \\
\hline Obstetrics, maternity & 6 & 4.69 \\
\hline Peds, PICU & 3 & 2.34 \\
\hline Psychiatry, mental health & 6 & 4.69 \\
\hline Public health & 29 & 22.66 \\
\hline Rural, acute & 6 & 4.69 \\
\hline Rural, public health & 1 & 0.78 \\
\hline Other & 1 & 0.78 \\
\hline \multicolumn{3}{|l|}{ Years of practice } \\
\hline$<5$ & 12 & 9.38 \\
\hline $5-9$ & 26 & 20.31 \\
\hline $10-19$ & 24 & 18.75 \\
\hline $20-29$ & 36 & 28.13 \\
\hline 30 or more & 30 & 23.44 \\
\hline \multicolumn{3}{|l|}{ Primary environment } \\
\hline Community & 46 & 35.93 \\
\hline Hospital & 74 & 57.81 \\
\hline Professional or government & 1 & 0.7 \\
\hline Residence care & 7 & 5.46 \\
\hline
\end{tabular}

\section{Subscale Reliability}

The reliability (internal consistency) of individual subscales were calculated using Cronbach's alpha and results are displayed in Table 2. One subscale, Faculty Interaction, showed a low alpha score of 0.370 . A low coefficient alpha can be caused by a small number of items or by non-unidimensionality (i.e., it is measuring more than one psychometric factor) (Tavakol \& Dennick, 2011). The Faculty Interaction subscale contained only three items: (1) I prefer the three-way evaluation process where the student and I are all involved, with the faculty member taking the lead. (2) I was satisfied with the number of times that the nursing faculty contacted me. (3) Meeting nursing faculty face to face is important to me.

Table 2

Internal Consistency of Subscales Measured by Cronbach's Alpha

\begin{tabular}{|c|c|c|c|c|}
\hline Subscale & Material & Student & Preparation & Faculty \\
\hline Alpha value & 0.790 & 0.870 & 0.850 & 0.370 \\
\hline
\end{tabular}


The wording of the first item in this subscale could have been perceived as measuring multidimensional characteristics, and each of these three items were designed to measure preceptors' preferences. Results of responses to the Faculty Interaction subscale statements indicated the statements elicited dichotomous responses; for instance, $40 \%$ of respondents disagreed and $60 \%$ agreed with statements. Because of these two features of this set of items, the subscale yielded low alpha scores, and these subscale results should not be used for decision making. However, the low alpha does not preclude single-question quantitative or qualitative analyses and refers only to subscale (i.e., grouped question) analyses.

\section{Preceptors' Perceptions Regarding Role Development and Support Initiatives}

Survey questions were grouped into four subscales: (1) preparation (representing the perceptions of preceptors regarding the overall satisfaction with preparation and support from nursing faculty, (2) materials (representing the perceptions of preceptors regarding adequacy of supplied material such as checklists and a manual, and preparation of evaluation documents), (3) student (representing the perceptions of preceptors regarding adequacy of support surrounding student learning objectives and evaluation, and (4) faculty interaction (representing the perceptions of preceptors regarding the importance of faculty support and interactions).

\section{Preparation Subscale}

The Preparation subscale is composed of the following questions/statements representing the perceptions of preceptors regarding the overall satisfaction with preparation/support from the nursing program: (1) I feel I have been adequately prepared for my role as a preceptor; (2) I was not provided with enough resources to enable me to carry out my role; (3) I was satisfied with the support I received from the program in helping me to evaluate students; (4) Overall I felt satisfied with the support by the faculty; and (5) Based on my experience I would be willing to be a preceptor again for the program.

The study results showed that overall, those with the least experience in preceptoring, the younger preceptors, and those with the fewest years of practice overall disagreed that they had been adequately prepared for their role. Significant differences were found in preparation subscale scores (see Table 3). Subscale score data shows significant differences between age $>60$ years and ages 30-39 years and 40-49 years, in both cases the $>60$ years subgroup performed better, with medium effect sizes. Years of practice category 10-19 years performed better than subgroups 5-9 years and 20-29 years, again with medium effect sizes.

\section{Table 3}

Significant Demographic Comparisons for the Preparation Subscale

\begin{tabular}{|l|c|c|c|c|c|c|}
\hline \multicolumn{1}{|c|}{ Scale } & Group size & $p$ value & Estimate & $\begin{array}{c}\text { Confidence } \\
\text { level } \\
\text { low }\end{array}$ & $\begin{array}{c}\text { Confidence } \\
\text { level } \\
\text { high }\end{array}$ & $\begin{array}{c}r . \\
\text { effect. } \\
\text { size }\end{array}$ \\
\hline $\begin{array}{l}\text { Age: } 60 \text { or more } \\
\text { vs 30-39 }\end{array}$ & 9 vs 30 & 0.044 & -5.712 & -11.424 & 0.000 & - \\
\hline $\begin{array}{l}\text { Age: } 60 \text { or more } \\
\text { vs } 40-49\end{array}$ & 9 vs 37 & 0.047 & -5.712 & -14.280 & 0.000 & - \\
\hline
\end{tabular}




\begin{tabular}{|l|c|c|c|c|c|c|}
\hline $\begin{array}{l}\text { Years of } \\
\text { practice: } 5-9 \text { vs } \\
10-19\end{array}$ & 26 vs 24 & 0.015 & 5.712 & 0.000 & 8.568 & 0.340 \\
\hline $\begin{array}{l}\text { Years of } \\
\text { practice: } 10-19 \\
\text { vs } 20-29\end{array}$ & 24 vs 36 & 0.035 & -5.712 & -11.424 & 0.000 & - \\
\hline
\end{tabular}

In addition, Table 4 shows significant differences in scores and proportions explicitly agreeing with the statement "I feel I have been adequately prepared for my role as a preceptor." The results revealed that approximately $30 \%$ of demographic categories did not agree that they were satisfied with the evaluation process support they received from the program.

\section{Table 4}

Significant Differences for "I Feel I Have Been Adequately Prepared for My Role as a Preceptor"

\begin{tabular}{|c|c|c|c|c|c|c|c|c|}
\hline $\begin{array}{l}\text { Demographic } \\
\text { group }\end{array}$ & $\begin{array}{l}\text { Group } \\
\text { size }\end{array}$ & $\begin{array}{c}p \\
\text { value }\end{array}$ & Estimate & $\begin{array}{c}r . \\
\text { effect. } \\
\text { size }\end{array}$ & $\begin{array}{l}\text { FET } p \\
\text { value }\end{array}$ & ES.h & $p 1$ & $p 2$ \\
\hline $\begin{array}{l}\text { Total sample } \\
\text { vs age } 20-29\end{array}$ & $\begin{array}{l}128 \mathrm{vs} \\
15\end{array}$ & 0.049 & 0 & -0.162 & 0.040 & -0.532 & 0.835 & 0.600 \\
\hline $\begin{array}{l}\text { Age: } 60 \text { and } \\
\text { over vs } 20- \\
29\end{array}$ & $\begin{array}{l}9 \mathrm{vs} \\
15\end{array}$ & 0.013 & -1 & -0.522 & 0.052 & -1.369 & 1.000 & 0.600 \\
\hline $\begin{array}{l}\text { Age: } 60 \text { and } \\
\text { over vs } 30- \\
49\end{array}$ & $\begin{array}{l}9 \mathrm{vs} \\
30\end{array}$ & 0.027 & -1 & -0.380 & 0.554 & -0.761 & 1.000 & 0.862 \\
\hline $\begin{array}{l}\text { Age: } 20-29 \\
\text { vs } 50-59\end{array}$ & $\begin{array}{l}15 \mathrm{vs} \\
37\end{array}$ & 0.045 & 1 & 0.282 & 0.048 & 0.680 & 0.600 & 0.886 \\
\hline $\begin{array}{l}\text { Acute vs } \\
\text { rural, acute }\end{array}$ & $\begin{array}{l}42 \mathrm{vs} \\
6\end{array}$ & 0.041 & 1 & 0.320 & 0.566 & 0.988 & 0.775 & 1.000 \\
\hline $\begin{array}{l}\text { Num. BScN } \\
0-1 \text { vs Num. } \\
\text { BScN >=10 }\end{array}$ & $\begin{array}{l}31 \mathrm{vs} \\
8\end{array}$ & 0.037 & 1 & 0.345 & 0.159 & 0.150 & 0.700 & 1.000 \\
\hline
\end{tabular}

Note: "p-value" represents the value of Wilcoxon Rank-Sum tests, "r .effect size" is size for Wilcoxon Rank-Sum tests. The column "FET. p-value" illustrates the p-value of Fisher's exact test, "ES.h" is the effect size for Fisher's Exact test, $\mathrm{h}$. Columns p1 and $\mathrm{p} 2$ are the proportions of the respective demographic categories being compared.

Table 5 presents results of Wilcoxon Rank-Sum and Fisher's exact tests on demographic subgroup responses to the statement "I was satisfied with the support I received from the program in helping me to evaluate students." The two significant results in Table 5 show $10 \%-15 \%$ of individuals in one demographic group that explicitly did not agree with the statement versus approximately $40 \%$ in another demographic group. In the total sample, approximately $30 \%$ of respondents did not clearly agree with the statement and this is broadly reflected across most demographic questions, with no obvious trends in experience or area of practice. Respondents from areas of practice that disagreed with this question in order of decreasing disagreement were 
acute; psychiatry, mental health; obstetrics, maternity; public health; community health, home care; rural, acute; and acute, critical care.

\section{Table 5}

Significant Demographic Comparisons for Individual Material Question: Preparation/Support for Evaluation

\begin{tabular}{|l|c|c|c|c|c|c|c|c|}
\hline \multicolumn{1}{|c|}{$\begin{array}{c}\text { Demographic } \\
\text { group }\end{array}$} & $\begin{array}{c}\text { Group } \\
\text { size }\end{array}$ & $\begin{array}{c}p \\
\text { value }\end{array}$ & Estimate & $\begin{array}{c}r \text {. effect. } \\
\text { size }\end{array}$ & $\begin{array}{c}\text { FET } \\
\text { p value }\end{array}$ & ES.h & $p 1$ & $p 2$ \\
\hline $\begin{array}{l}\text { Age: } 60 \text { or more } \\
\text { vs } 40-49\end{array}$ & 9 vs 37 & 0.049 & -1 & -0.293 & 0.124 & -0.729 & 0.889 & 0.581 \\
\hline $\begin{array}{l}\text { Years of } \\
\text { practice: } 5-9 \text { vs } \\
10-19\end{array}$ & 26 vs 24 & 0.042 & 1 & 0.288 & 0.051 & 0.647 & 0.583 & 0.864 \\
\hline
\end{tabular}

The results further revealed little agreement among demographic categories about overall satisfaction with support from the program. The specific areas of practice that explicitly did not feel supported were those respondents working in psychiatry/mental health, acute, public health, community health, and home care settings. However, in response to a question about whether preceptors would be willing to preceptor again for the program, approximately $15 \%$ of respondents indicated they were neutral (neither agreed nor disagreed) when answering the question, while another $10 \%$ of the sample strongly disagreed with the statement that they would preceptor again. Respondents who were strongly against preceptoring for the program in the future were from the areas of psychiatric/mental health, public health, and community health/home care, and those who had preceptored students for 20-29 years.

\section{Materials Subscale}

The materials subscale was composed of statements about perceptions of preceptors regarding adequacy of supplied material such as checklists, manuals, and preparation to complete evaluation documents. The results revealed that the majority (approximately 90\%) of the respondents agreed that the preceptor and student checklists were beneficial. While approximately $80 \%$ of respondents agreed the faculty check list was beneficial, $20 \%$ of respondents from practice areas including acute care, obstetrics and maternity care, community health, home care, and public health disagreed that the faculty check list was beneficial. Interestingly, $50 \%$ of respondents working in psychiatry and mental health settings reported neutral responses to this item.

Table 6 demonstrates the statistically significant differences between demographic subgroups for the Materials subscale. Significant differences in the Materials subscale responses were noted for the following demographic subgroups, as illustrated with the following points: (a) Respondents ages 60 and over rated the materials as adequate more often than younger respondents, with small to medium effect sizes; (b) respondents in the general category of community workplaces perceived the materials as less adequate than preceptors working in hospitals; (c) respondents in the psychiatry and mental health areas of practice rated the adequacy of materials significantly worse than respondents working in pediatric areas and pediatric intensive care units (PICU); (d) respondents with fewer years of practice, specifically those with 5-9 years and 20-29 years perceived the materials as less adequate more frequently than respondents with $>30$ years or those with $<5$ years of practice; and (e) respondents who had 
preceptored 2-4 students rated the materials as less adequate than respondents who had preceptored $>10$ students.

\section{Table 6}

Significant Demographic Comparisons of Responses Regarding Adequacy of Material

\begin{tabular}{|l|c|r|r|r|r|r|}
\hline \multicolumn{1}{|c|}{ Scale } & $\begin{array}{c}\text { Group } \\
\text { size }\end{array}$ & $\begin{array}{c}p \\
\text { value }\end{array}$ & Estimate & $\begin{array}{c}\text { Conf. } \\
\text { low }\end{array}$ & \multicolumn{1}{c|}{$\begin{array}{c}\text { Conf. } \\
\text { high }\end{array}$} & $\begin{array}{c}r \text { effect } \\
\text { size }\end{array}$ \\
\hline Age: total sample vs 60 or more & 128 vs 9 & 0.030 & 4.760 & 0.000 & 14.280 & 0.183 \\
\hline Age: 60 or more vs 30-39 & 9 vs 30 & 0.012 & -9.520 & -19.040 & 0.000 & -0.396 \\
\hline Age: 60 or more vs 40-49 & 9 vs 37 & 0.028 & -4.760 & -14.280 & 0.000 & -0.320 \\
\hline $\begin{array}{l}\text { Area of practice: community vs } \\
\text { hospital }\end{array}$ & 46 vs 74 & 0.011 & 4.760 & 0.000 & 9.520 & 0.231 \\
\hline $\begin{array}{l}\text { Area of practice: acute vs public } \\
\text { health }\end{array}$ & 42 vs 29 & 0.031 & -4.760 & -9.520 & 0.000 & -0.256 \\
\hline $\begin{array}{l}\text { Area of practice: Peds, PICU vs } \\
\text { Psych, mental health }\end{array}$ & 3 vs 6 & 0.048 & -14.280 & -23.800 & 0.000 & -0.703 \\
\hline Years of practice: <5 vs 5-9 & 12 vs 26 & 0.013 & -9.520 & -19.040 & -4.760 & -0.399 \\
\hline Years of practice: <5 vs 20-29 & 12 vs 36 & 0.024 & -9.520 & -14.280 & 0.000 & -0.325 \\
\hline Years of practice: 5-9 vs 30 or more & 26 vs 30 & 0.005 & 9.520 & 4.760 & 14.280 & 0.368 \\
\hline $\begin{array}{l}\text { Years of practice: } 20-29 \text { vs 30 or } \\
\text { more }\end{array}$ & 36 vs 30 & 0.020 & 4.760 & 0.000 & 9.520 & 0.286 \\
\hline Num. BScN 2-4 v. Num. BScN >=10 & 62 vs 8 & 0.027 & 9.520 & 0.000 & 14.280 & 0.263 \\
\hline
\end{tabular}

The results further indicate that more experienced respondents (those who are older, have more than 30 years of practice, and those who had preceptored more than 10 students) more frequently agreed that the materials were adequate on Materials subscales. Respondents with less than 5 years of practice rated the adequacy of materials higher than those with 5-9 and 20-29 years of experience, and respondents in community or non-hospital settings (psychiatry/mental health and public health settings) indicated they perceived materials were less adequate.

Regarding the student clinical skills inventory list, study results indicated approximately $60 \%$ of the total sample agreed that the list was not confusing to use, whereas approximately $40 \%$ of the total sample indicated the list was confusing to use. Respondents with the fewest years of practice, and respondents in the 60 years of age and older category rated the skills list as less confusing compared to respondents in other categories. Respondents working in community health, home care, psychiatry, mental health, pediatrics, and PICU areas most frequently rated the skills inventory lists as confusing.

Participants rated the evaluation document as part of the materials subscale. The results identified that while approximately $90 \%$ of the respondents agreed that the manual provided adequate information to complete the evaluation form, approximately $10 \%$ of respondents working in acute and critical care, pediatrics, PICU, public health, rural and community health/home care disagreed with this statement. Respondents from the areas that did not explicitly disagree with the question had low sample sizes: psychiatric, mental health; long-term care; rural, public health; and obstetrics, maternity. However, no significant differences in scores or proportions agreeing with the statement were found. The results further revealed that $50 \%$ of preceptors indicated that the evaluation documents were time consuming, and $20 \%$ of respondents were neutral with their response. 


\section{Student Subscale}

The Student subscale comprised four items, soliciting the perceptions of preceptors regarding adequacy of support surrounding student learning objectives and evaluation. The items were (1) the course outcomes were well defined and easily understood; (2) student scope of practice was well explained; (3) my role in facilitating and assessing student learning in the clinical environment was clearly explained; and (4) expectations regarding student learning in the clinical environment were clearly explained. Approximately $90 \%$ of responses indicated that preceptors understood course outcomes, although approximately $20 \%$ of respondents did not agree that their role was explained clearly to them. These respondents were preceptors who (a) had less than 10 years of practice and (b) worked in the following areas of practice: public health; psychiatric, mental health; acute; acute, critical; and home care/community. Additionally, $40 \%$ of respondents working in psychiatric or mental health areas disagreed that the expectations regarding student learning in the clinical environment were clearly explained to them. As shown in Table 7, statistically significant differences occurred among demographic subgroups for the Student subscale.

\section{Table 7}

Significant Demographic Comparisons for Student Subscale

\begin{tabular}{|l|c|c|c|c|c|c|}
\hline \multicolumn{1}{|c|}{ Scale } & $\begin{array}{c}\text { Group } \\
\text { size }\end{array}$ & $\begin{array}{c}p \\
\text { value }\end{array}$ & Estimate & $\begin{array}{c}\text { Conf. } \\
\text { low }\end{array}$ & $\begin{array}{c}\text { Conf. } \\
\text { high }\end{array}$ & $\begin{array}{c}r \text { effect } \\
\text { size }\end{array}$ \\
\hline Acute vs long-term care & 42 vs 7 & 0.045 & 6.120 & 0.000 & 12.240 & 0.285 \\
Long-term care vs peds, & 7 vs 3 & 0.042 & -12.240 & -20.400 & 0.000 & -0.653 \\
PICU & & & & & & \\
\hline
\end{tabular}

\section{Faculty Interaction Subscale}

The Faculty Interaction subscale contained three items: (1) I prefer the three-way evaluation process where the student and I are all involved, with the faculty member taking the lead. (2) I was satisfied with the number of times that the nursing faculty contacted me. (3) Meeting nursing faculty face to face is important to me. With regard to the importance of face-to-face meetings, type of faculty support, and interactions, approximately $80 \%$ of respondents agreed that they were satisfied with the number of times nursing faculty contacted them. Those who were not satisfied with the contact were from areas including obstetrics/maternity, acute care, community health/home care, and public health. The importance of meeting faculty face to face had varied results: $60 \%$ of respondents were in favour of meeting faculty, while $40 \%$ were not. Preceptors in rural areas of practice were generally against the idea, while those who were commonly in favor of the idea were obstetrics/maternity and pediatrics/PICU. All areas of practice in almost all demographic categories in general were divided on the importance of meeting face to face. The results further showed that the more experienced preceptors preferred or were neutral with the three-way evaluation conference led by faculty. There was a general trend of the less experienced preceptors not being satisfied with the number of times faculty contacted them. 
The results further revealed statistically significant differences between demographic subgroups for the faculty Interaction subscale scores with moderate effect sizes (Table 8). In most cases, differences in demographics with robust sample sizes are shown. These several differences highlight the dichotomous nature of this subscale, which the reader may recall had very low Cronbach's alpha results. This is most likely due to the statement "Meeting nursing faculty face to face is important to me," which was a contentious question with strongly divided results.

\section{Table 8}

Significant Demographic Comparisons for Faculty Interaction Subscale

\begin{tabular}{|l|c|c|c|c|c|c|}
\hline \multicolumn{1}{|c|}{ Scale } & $\begin{array}{c}\text { Group } \\
\text { size }\end{array}$ & $\begin{array}{c}p \\
\text { value }\end{array}$ & Estimate & $\begin{array}{c}\text { Conf. } \\
\text { low }\end{array}$ & $\begin{array}{c}\text { Conf. } \\
\text { high }\end{array}$ & $\begin{array}{c}r \text { effect. } \\
\text { size }\end{array}$ \\
\hline $\begin{array}{l}\text { Age: } 60 \text { or more vs } 30- \\
49\end{array}$ & 9 vs 30 & 0.042 & -7.140 & 14.280 & 0.000 & -0.325 \\
\hline $\begin{array}{l}\text { Area of practice: } \\
\text { community health, home } \\
\text { care vs long-term care }\end{array}$ & 12 vs 7 & 0.049 & 10.710 & 0.000 & 14.280 & 0.453 \\
\hline $\begin{array}{l}\text { Years of practice: 5-9 vs } \\
10-19\end{array}$ & 26 vs 24 & 0.020 & 7.140 & 0.000 & 10.710 & 0.328 \\
\hline
\end{tabular}

\section{Discussion}

Results of this study indicate that there are correlations among the less experienced preceptors, role explanations, and role preparation with the need for increased faculty support. These findings are consistent with findings in the literature: preceptors require preparation and support for their important role in teaching and evaluating students (Luhanga et al., 2008; McSharry \& Lathlean, 2017). It cannot be assumed that because of their clinical expertise nurse clinicians are necessarily good teachers, and hence there is a need to prepare preceptors with the necessary knowledge and skills to effectively carry out the preceptor role (e.g., Horton et al., 2012; Luhanga et al., 2010). In a study conducted by Panzavecchia and Pearce (2014) all the participants indicated they had received no formal preparation for their role as preceptors. McSharry and Lathlean (2017) explored the clinical teaching and learning within the preceptorship model in an acute care setting in Ireland and concluded that preceptors need extensive educational preparation and support to ensure they have the pedagogical competencies necessary to facilitate student learning. Likewise, Lazarus (2016) concurred that novice preceptors, in particular, need education and support to learn their new role, while experienced preceptors desire continued support and further role development. After attending the preparatory courses, preceptors in a study by Mårtensson et al. (2016) reported increased confidence in the educational and supervisory role.

Kennedy (2019) compared nurse preceptors who have had formal educational education with nurses who had not. While the findings were consistent with those reported in the literature of previous studies, differences were found between the two groups of nurses. The study findings revealed that nurse preceptors with formal education tended to provide practice based on evidence-based practice standards, had more understanding of the preceptor role and its components, were motivated, and used more teaching strategies than those without formal preceptor preparation. Preceptors who had attended preceptor education reportedly "felt more prepared for their roles, had fewer challenges in carrying out preceptor responsibilities, and 
exhibited commitment to their professional development, especially when benefits and support were available" (Kennedy, 2019, p. 107). Preceptors in the same study further indicated lack of managerial support in preparation, workload, sufficient time with their preceptees, support of ongoing education, and availability of support (Kennedy, 2019). Likewise, L'Ecuyer and colleagues (2018) suggest that "the work of preceptors is a difficult and complex process, and they must be given the tools they need to accomplish their responsibilities. In addition, they must be monitored, nurtured, and supported" (p. 140). Therefore, preceptor support from both faculty and unit managers is critical and is a key element in preceptor retention. For example, ongoing communication with, and support and guidance from faculty is particularly valued in the initial preceptor educational period, during evaluations of student progress (Dahlke et al., 2016; Lazarus, 2016), and when dealing with challenging students (Lazarus, 2016; Luhanga et al., 2008; Luhanga et al., 2015).

Preceptors are expected to be responsible for evaluating students, yet they receive little, if any, preparation (Seldomridge \& Walsh, 2006). Seldomridge and Walsh (2006) further explain that if clinical evaluation instruments are used, which is the case in most nursing programs, "these may be time consuming to complete, may encourage 'global' ratings, and may use terminology not easily understood by preceptors" (p. 172). Similarly, Butler et al. (2011) reported that preceptors in their study had difficulty understanding and interpreting the language used in the competence assessment and assessed knowledge and attitudes more often than skills.

The results from this study affirmed that faculty do not provide the support, education, and guidance that is needed for successful preceptorship to occur. The role of nursing faculty, particularly of faculty advisors, is pivotal to student success in the clinical teaching and learning context (Lazarus, 2016; Luhanga et al., 2015). While it is assumed that faculty have the necessary knowledge and skills required for supporting and guiding the preceptors, specifically, when the preceptor is faced with making critical decisions about a student who is unsafe (Luhanga et al., 2008), there is evidence in the literature that many faculty advisors are not academically prepared to teach and evaluate the clinical component of nursing education programs, particularly in preceptorship-based clinical courses (Luhanga et al., 2015; Seldomridge \& Walsh, 2006; Yonge et al., 2003). Yonge et al. (2003) observed that faculty had little knowledge about the preceptors, had insufficient information to provide preceptors, and felt limited support from colleagues when the time came for final evaluations of student performance.

As such, team development may be needed to improve faculty's knowledge and confidence in order for them to meet and/or identify the needs of the preceptors. Participants in this study suggested that the $\mathrm{BScN}$ program re-examine the current evaluation document that is being used and make revisions that support preceptors to fulfil this part of their role.

It is worth noting one common theme that emerged from the results specifically from preceptors who worked in community and psychiatry. Even though this group of respondents made up a smaller portion of the research participants, it is important to identify that these clinical areas had less than positive results in three areas: (a) faculty support, (b) material resources, and (c) role clarification. Therefore, there is a need for nursing programs to revise resources and support to explicitly meet the needs of the preceptors working in these areas of practice.

Lastly, the preceptors in this study largely viewed their role within this program positively, and it is encouraging that a majority of preceptors indicated that they would be a preceptor another 
time for the program. However, the results did not indicate why some of the preceptors would not take on that role again.

\section{Limitations to the Study}

There may be some limitations to this study. First, the focus on a single collaborative $\mathrm{BScN}$ program in one province of Canada means that the results cannot be generalized to other nursing programs. Wording of the question may have had some influence on the responses: (a) negatively phrased questions, (b) vague terms such as "enough" as these terms can be interpreted in a variety of ways, and (c) misinterpretation of or difficult to understand terms such as "agree," "strongly agree," "disagree," or "strongly disagree."

\section{Conclusions and Recommendations}

The results of this study are consistent with those from previous research indicating that preceptors play a critical role in providing value for any educational institution. It is important that faculty take an active role to create and sustain the environment of support for preceptors, and to have a deep understanding of their own role to be able to guide/educate preceptors. Having a better understanding of the preceptors' perspectives regarding what they need to fulfil their role as a preceptor is the cornerstone of preceptor satisfaction. Enhancing satisfaction for preceptors can encourage the recruitment and retention that nursing schools require. The study results suggest that additional faculty education and support are needed to ensure faculty and preceptors have a better understanding of the preceptors' roles. There is need for further development of preceptor manuals to include relevant material for specific clinical areas, a review of evaluation documents, and increased support for younger and least experienced preceptors.

Based on the study results, further research is recommended in the following areas: (1) explore the perceptions and experiences of younger/less experienced preceptors regarding types of skills they perceive they need to be effective in their role; (2) identify what different resources are needed for preceptors working in different clinical settings; (3) determine if there are existing relationships between types of workplace practice and preceptors' perceptions of role development and support; and (4) determine whether preceptors experience burnout and fatigue related to volunteering as a preceptor too many times. 


\section{References}

Blum, C. A. (2014). Evaluating preceptor perception of support using educational podcasts. International Journal of Nursing Education Scholarship, 11(1), 1-8.

Bowen, A., Fox, R., \& Burridge, C. (2012). Preceptorship: Making a difference. Journal for Nurses in Staff Development, 28(2), E12-E15.

Broadbent, M., Moxham, L., Sander, T., \& Swyer, T. (2014). Supporting bachelor of nursing students within the clinical environment: Perspectives of preceptors. Nurse Education in Practice, 14(4), 327-446.

Butler, M. P., Cassidy, I., Quillinan, B., Fahy, A., Bradshaw, C., Tuohy, D., O'Connor, M., McNamara, M. C., Egan, G., \& Tierney, C. (2011). Competency assessment methodsTool and processes: A survey of nurse preceptors in Ireland. Nurse Education in Practice, 11(5), 298-303. https://doi.org/10.1016/j.nepr.2011.01.006

Dahlke, S., O’Connor, M., Hannensson, T., \& Cheethan, K. (2016). Understanding clinical nursing education: An exploratory study. Nurse Education in Practice, 17, 145-152. https://doi.org/10.1016/j.nepr.2015.12.004

DeWolfe, J. A., Laschinger, S., \& Perkins, C. (2010). Preceptors' perceptive on recruitment, support, and retention of preceptors. Journal of Nursing Education, 49(4), 198-206.

Dibert, C., \& Goldenberg, D. (1995). Preceptors' perceptions of benefits, rewards, supports and commitment to the preceptor role. Journal of Advanced Nursing, 21(16), 1144-1151.

Haggerty, C., Halloway, K., \& Wilson, D. (2012). Entry into nursing practice preceptor education and support: Could we do it better? Nursing Praxis in New Zealand, 28(1), $30-41$.

Hautala, K. T., Saylor, C. R., \& O’Leary-Kelley, C. (2007). Nurses' perceptions of stress and support in the preceptor role. Journal for Nurses in Staff Development, 23(2), 64-70.

Horton, C. D., DePaoli, S., Hertach, M., \& Bower, M. (2012). Enhancing the effectiveness of nurse preceptors. Journal for Nurses in Staff Development, 28(4), E1-7. https://doi.org/10.1097/NND.0b013e31825dfb90

Hyrkäs, K., \& Shoemaker, M. (2007). Changes in the preceptor role: Re-visiting preceptors' perceptions of benefits, rewards, support and commitment to the role. Journal of Advanced Nursing, 60(5), 513-524.

Kalischuk, R. G., Vandenberg, H., \& Awosoga, O. (2013). Nursing preceptors speak out: An empirical study. Journal of Professional Nursing, 29(1), 30-38. https://doi.org/10.1016/j.profnus.2012.04.008

Kennedy, A. (2019). Nurse preceptors and preceptor education: Implications for preceptor programs, retention Strategies, and managerial support. MEDSURG Nursing, 28(2), 107-113.

Larocque, S., \& Luhanga, F. L. (2013). Exploring the issue of failure to fail in nursing program. International Journal of Nursing Education Scholarship, 10(1), 1-8. 
Lazarus, J. (2016). Precepting 101: Teaching strategies and tips for success for preceptors. Journal of Midwifery \& Women's Health, 61(S1), 11-21. https://doi.org/10.1111/jmwh.12520.

L'Ecuyer, K. M., Hyde, M. J., \& Shatto, B. J. (2018). Preceptors' perception of role competency. The Journal of Continuing Education in Nursing, 49(5), 233-240.

Lee, Y. W., Lin, H. L., Tseng, H. L., Tsai, Y. M., \& Lee-Hsieh, J. (2017). Using training needs assessment to develop a nurse preceptor-centered training program. Journal of Continuing Education in Nursing, 48(5), 220-229. https://doi.org/10.3928/0022012420170418-0

Liu, M., Lei, Y., Mingxia, Z., \& Hoabin, Y. (2010). Lived experiences of clinical preceptors: A phenomenological study. Nurse Education Today, 30(8), 804-808.

Luhanga, F. L., Dickieson, P., \& Mossey, S. D. (2010). Preceptor preparation: An investment in the future generation of nurses. International Journal of Nursing Education Scholarship, 7(1), Article 38. https://doi.org/10.2202/1548-923X.1940

Luhanga, F. L., Koren, I., Yonge, O., \& Myrick, F. (2015). The role of faculty advisors in preceptorship: From a faculty point of view. Journal of Nursing Education and Practice, 5(1), 85-94.

Luhanga, F., Yonge, O., \& Myrick, F. (2008). Precepting an unsafe student: The role of faculty. Nurse Education Today, 28(2), 227-231.

Mårtensson, G., Löfmark, A., Mamhidir, A.-G., \& Skytt, B. (2016). Preceptors’ reflections on their educational role before and after a preceptor preparation course: A prospective qualitative study. Nurse Education in Practice, 19, 1-6. https://doi.org/10.1016/j.nepr.2016.03.011

McCarthy, B., \& Murphy, S. (2010). Preceptors' experience of clinically educating and assessing undergraduate nursing students: An Irish context. Journal of Nursing Management, 18(2), 234-244.

McSharry, E., \& Lathlean, J. (2017). Clinical teaching and learning within a preceptorship model in an acute care hospital in Ireland; A qualitative study. Nurse Education Today, 51, 73-80. https://doi.org/10.1016/j.nedt.2017.01.007

Myrick, F., Caplan, W., Smitten, J., \& Rusk, K. (2011). Preceptor/mentor education: A world of possibilities through e-learning technology. Nurse Education Today, 31(3), 263-267. https://doi.org/10.1016/j.nedt.2010.10.026

Myrick, F., \& Yonge, O. (2005). Nursing preceptorship: Connecting practice and education. Lippincott Williams \& Wilkins.

Panzavecchia, L., \& Pearce, R. (2014). Are preceptors adequately prepared for their role in supporting newly qualified staff? Nurse Education Today, 34 (7), 1119-1124. https://doi.org/10.1016/j.nedt.2014.03.00

Polit, D. F., \& Beck, C. T. (2017). Nursing research: Generating and assessing evidence for nursing practice (10th ed.). Wolters Kluwer. 
R Core Team. (2014). R: A language and environment for statistical computing. R Foundation for Statistical Computing.

Revelle, W. (2015). Psych: Procedures for psychological, psychometric, and personality research. Northwestern University.

Rice, S., Winter, S. R., Doherty, S., \& Milner, M. (2017). Advantages and disadvantages of using Internet-based survey methods in aviation-related research. Journal of Aviation Technology and Engineering, 7(1), 58-65. https://doi.org/10.7771/2159-6670.1160

Tavokol, M., \& Dennick, R. (2011). Making sense of Cronbach's alpha. International Journal of Medical Education, 2, 53-55. https://www.ijme.net/archive/2/cronbachs-alpha/

Seldomridge, L. A., \& Walsh, C. M. (2006). Evaluating student performance in undergraduate preceptorships. Journal of Nursing Education, 45(5), 169-176.

Yonge, O., Ferguson, L., Myrick, F., \& Haase, M. (2003). Faculty preparation for the preceptorship experience: The forgotten link. Nurse Educator, 28(5): 210-211.

Yonge, O., Myrick, F., \& Ferguson, L. (2011). The challenge of evaluation in rural preceptorship. Online Journal of Rural Nursing \& Health Care, 11(2), 3-15. 